\title{
Trabalho de Conclusão de Curso em Ciência da Computação
}

\author{
Magali Maria de Araújo Barroso \\ mbarroso@unibh.br \\ Centro Universitário de Belo Horizonte - www.unibh.br
}

\begin{abstract}
Resumo - São apresentadas, neste artigo, diretrizes metodológicas que apóiam o aluno de Ciência da Computação na elaboração do Trabalho de Conclusão de Curso. Também são recomendados certos cuidados na escolha do tema e levantada uma série de questões que estimulam o aluno para o desenvolvimento da pesquisa. Ainda são sugeridos alguns tipos de trabalhos de graduação na área da Computação e descritas as dinâmicas da orientação e da avaliação de atividades discentes.

Palavras-chave-Metodologia, TCC, Computação.
\end{abstract}

Abstract - This article presents methodological guidelines to be used as support by Computer Science students in the elaboration of their required Course Conclusion Paper. It also recommends certain diligence on theme choices, and raises a number of questions aimed at stimulating the student in the research development. Additionally, different types of Computer Science projects are suggested, as examples, and the dynamics of the orientation and evaluation activities are described.

keywords - Methodology, Course Conclusion Paper, Computer Science Course

\section{INTRODUÇÃO}

O Trabalho de Conclusão de Curso (TCC) é uma exigência das diretrizes curriculares dos cursos de graduação em Ciência da Computação. Particularmente no Centro Universitário de Belo Horizonte - Uni-BH, o TCC é realizado pelos alunos nos dois últimos períodos, enquanto cursam as disciplinas Projeto Orientado em Computação I - POC I e Projeto Orientado em Computação II - POC II. O objetivo deste artigo é apresentar diretrizes metodológicas para que o aluno desenvolva sua pesquisa e registre o resultado do estudo, seguindo o padrão estabelecido pelo colegiado do curso.

Umberto Eco pontua em [4] que, de um trabalho científico, "nada se desperdiça". Ao desenvolvê-lo o estudante tem a oportunidade de pesquisar, priorizando um tema de seu interesse, aplicando e expandindo os conhecimentos adquiridos durante o curso.

Em todas as etapas do processo, desde a escolha da área temática, e a especificação do escopo do problema a ser resolvido, explicitando as questões a ele inerentes, o aluno é orientado e estimulado à reflexão e à crítica sobre o assunto pesquisado. Ao realizar a revisão bibliográfica busca-se especificar o conjunto de métodos e técnicas que solucionam o problema. Após a implementação da metodologia, obtém-se os resultados, faz-se a análise dos mesmos e, finalmente, apresenta-se a conclusão.

Todo este percurso é feito dentro de prazos estipulados em um cronograma preestabelecido. Em paralelo à pesquisa, o aluno elabora o artigo científico, cujo modelo se encontra em [3], registrando o desenvolvimento do trabalho, de modo que finalizado o projeto poucos ajustes tornam-se necessários para concluir o documento monográfico. Ao final da segunda disciplina, o artigo científico é apresentado oralmente em seminário específico e em mídia digital para a avaliação de uma banca examinadora. Os trabalhos aprovados são publicados na Revista Eletrônica POC, disponibilizada no site do curso.

\section{RELEVÂNCIA DO TCC}

A realização do TCC é importante para o estudante, sob vários aspectos, do ponto de vista:

- prático - esta é uma exigência a ser cumprida para a conclusão do curso, atendendo ao Projeto Pedagógico do Curso de Ciência da Computação do Uni$\mathrm{BH}$ [14];

- acadêmico - a oportunidade de desenvolver um projeto, orientado por um

\begin{tabular}{l|l|l|l|l} 
e-xacta & Belo Horizonte & ISSN 1984-3151 & www.unibh.br/revistas/exacta & v. 2, n. 1, jun 2009
\end{tabular} 
professor da área, desde sua concepção até a obtenção e discussão dos resultados, utilizando metodologia científica no aprofundamento e/ou aplicação de conhecimentos vistos no curso. Esta experiência é enriquecedora para o crescimento pessoal do aluno, por permitir sua vivência em todas as fases do projeto, dando-lhe subsídios para aplicá-la em situações assemelhadas em sua atuação profissional;

- científico - por contribuir para o desenvolvimento científico-tecnológico do estudante, o que diretamente influencia na constante atualização dos docentes do curso, corroborando para o fortalecimento da Instituição e da comunidade científica do país.

- político - ao buscar a solução de um problema, o estudante desenvolve o entendimento da universalidade do meio em que vive, ao se inteirar de conhecimentos da área em que a situaçãoproblema se vincula. Caso os resultados obtidos estendam seu alcance até a sociedade, sua realização torna-se efetivamente prazerosa e educativa por privilegiar "a face cívica da cidadania, pela qual o indivíduo se eleva ao patamar da cooperação, da solidariedade" [10] e vivencia a aplicabilidade do conhecimento adquirido na academia para além dela.

\section{A ESCOLHA DO TEMA}

O aluno de Ciência da Computação bem sabe da importância dos conhecimentos e habilidades adquiridos no curso para sua inserção ou manutenção no mercado de trabalho. Tendo a computação como atividade fim, conforme consta em [14], o curso de graduação forma recursos humanos para o desenvolvimento científico e tecnológico da área. Nada mais lógico que o aluno eleja o computador como ator principal de sua produção final, enquanto graduando.
O estudante deve ser criterioso ao selecionar o tema que irá abordar no desenvolvimento de seu projeto em computação. A escolha se inicia com a motivação e a curiosidade do estudante em pesquisar aquele assunto em profundidade. Muitos são os caminhos para fazê-lo; o tema pode surgir por intermédio de leituras de livros ou revistas especializadas, de circunstâncias pessoais ou necessidades profissionais, de uma palestra ou comunicação em congresso, por sugestões de profissionais ou professores vinculados à área.

A adequação do orientador também é muito importante. Ele deve ser um professor atuante na área da pesquisa pretendida, ter disponibilidade e afinidade com o orientando, já que formarão uma equipe para trabalhar durante dois semestres. Outros fatores a serem observados:

- adaptabilidade - o tema deve estar ao alcance do estudante, compatível com sua formação intelectual e com os recursos disponibilizados pela instituição;

- aplicabilidade - o estudo deve, sempre que possível, possibilitar a resolução de um problema real, concreto;

- exeqüibilidade - o desenvolvimento do trabalho deve ser viável, obedecendo os prazos estipulados;

- acessibilidade - o acervo bibliográfico disponível sobre o assunto deve atender às necessidades do estudante.

Pádua afirma em [18] que "Pesquisar é toda atividade voltada para a solução de problemas" e esse deve ser o espírito do estudante ao dar início ao projeto de fim de curso - investigar um dado assunto, objetivando identificar um problema a ser resolvido. $\mathrm{O}$ ato de selecionar conduz à restrição, isto é, faz-se a delimitação do estudo do tema, vislumbrando sua extensão e profundidade. $\mathrm{O}$ enunciado do problema direciona a busca do marco teórico que subsidia sua solução, identifica os dados a serem 
considerados, estabelece o tipo de resultado que a pesquisa suscita.

\section{DinÂMICA PARA O DESENVOLVIMENTO DO PROJETO}

O desenvolvimento do trabalho de conclusão de curso deve estar objetivamente ligado ao problema a ser resolvido. Um roteiro básico para a elaboração preliminar do projeto é sugerido a seguir:

- defina o tema a ser pesquisado e estabeleça, junto ao orientador, o problema a ser investigado, relacionando as questões que devem ser respondidas para identificar o produto final do trabalho, apontando os objetivos e a justificativa da escolha;

- faça a seleção do material bibliográfico a ser pesquisado;

- elabore o cronograma das ações que deve seguir para compor o trabalho;

- estude os textos selecionados e faça a documentação dos mesmos;

- especifique a metodologia a ser utilizada. $\mathrm{Ou}$, estabeleça as estratégias para solucionar o problema proposto, identificando os recursos necessários para a coleta dos dados e obtenção dos resultados;

- resolva o problema, analisando os resultados e apontando facilidades e/ou dificuldades encontradas;

- elabore o artigo científico seguindo as normas específicas;

- componha a apresentação oral.

O estudante deve se habituar a fazer perguntas e tentar respondê-las até que o tema em estudo esteja suficientemente conhecido. Algumas ações e questionamentos que dão suporte ao desenvolvimento de cada uma das fases que compõem o trabalho científico encontram-se a seguir:

1. Qual o tema do projeto? Identifique a área e sub-área nas quais o projeto se insere.

2. O que fazer? Qual é o problema a resolver? Enuncie o problema delimitando seu escopo, isto é, explicitando sua extensão e profundidade.

3. Faça o levantamento bibliográfico que dê suporte à fundamentação teóricometodológica para solucionar o problema. Identifique as fontes de pesquisa: livros, periódicos científicos, jornais, revistas, dicionários, artigos, etc, que tratam do tema da pesquisa.

4. Selecione o material bibliográfico que efetivamente será consultado. Faça a leitura crítica e a documentação deste material.

5. No momento em que o conhecimento sobre o problema estiver mais sedimentado é hora do estudante criar seu próprio roteiro de trabalho, especificando as fases a serem cumpridas e elaborar $\mathrm{o}$ cronograma do projeto, indicando o tempo a ser destinado para completar cada etapa que o compõe. O cronograma do aluno deve estar em sintonia com o das disciplinas POC I e POC II.

6. Martins em [15] ensina que raramente um trabalho científico não sofre modificações à medida em que ele se desenvolve. Por serem previsíveis, há que se fazer a correção de rota na configuração original do projeto, incorporando as novas exigências observadas, bem como a reestruturação do cronograma das atividades.

7. Qual é o histórico do problema? Pesquise os antecedentes do problema.

8. Se for o caso, localize a situaçãoproblema, vinculando-a, temporal e geograficamente.

9. Especifique os motivos que incentivaram a escolha do tema, isto é, a motivação do estudo.

10. Qual a relevância de seu trabalho?

11. Justifique a elaboração de seu trabalho, respondendo à questão: Porque fazer?

12. Especifique os objetivos do projeto, em resposta à questão: Para que fazer? Os objetivos se classificam em: Geral e 
Específicos. O Objetivo Geral é único e ele deve inspirar o título do trabalho, como ensina Michel em [16]. Já os Objetivos Específicos estão relacionados aos subproblemas, que compõem aquele que se busca solução.

13. Que dados estão disponíveis? Identifique o acervo de informações relacionadas à situação-problema.

14. De que forma os dados serão coletados?

15. De que forma os dados e a solução podem ser quantificados? Se for o caso atribua valores aos elementos quantificáveis, especificando as razões que justifiquem a escolha dos mesmos.

16. Qual é a metodologia utilizada para solucionar o problema? Responda à questão: Como fazer? Se for o caso faça a modelagem matemática do problema.

17. Que recursos são necessários? Responda à questão Com que fazer?

18. Qual é a fundamentação teórica que conduz à solução? Identifique o Marco Teórico.

19. Quais os resultados obtidos?

20. Faça a análise e/ou adequação dos resultados.

21. Quais são as conclusões e/ou recomendações? Nesta fase certifique-se do cumprimento dos objetivos e procure identificar trabalhos futuros.

\section{TIPOS BÁSICOS DE PROBLEMAS DA ÁREA DE CIÊNCIA DA COMPUTAÇÃO}

As formas mais comuns de trabalhos em Computação são:

- Projeto de um algoritmo, teoricamente fundamentado, que resolva um dado problema;

- Implementação de um algoritmo já existente, vinculando sua utilização à modelagem de uma situação-problema, fazendo a adequação dos resultados obtidos à realidade;

- Elaboração de um Aplicativo em um ambiente computacional específico;
- Elaboração de um Sistema de Computação para gerenciar um serviço;

- Comparação entre a adequação de dois ou mais métodos para a resolução de um problema;

- Pesquisa bibliográfica sobre um tema que possibilite a organização do desenvolvimento das descobertas científicas sobre ele na linha do tempo;

- Desenvolvimento de Aplicações envolvendo Banco de Dados.

- Estudo aprofundado de um artigo científico com implementação de algoritmos nele abordados.

\section{PESQUISA BIBLIOGRÁFICA}

No levantamento bibliográfico o estudante fará um apanhado geral das referências bibliográficas sobre o assunto. De posse desse material faz-se o que Pádua [18], denomina de Leitura de Reconhecimento em resumos, prefácios, sumários, introduções e conclusões para permitir a seleção da bibliografia básica, aquela que será explorada para subsidiar o trabalho científico. Em seguida, deve ser feita a Leitura Criteriosa do material escolhido, procurando identificar elementos teóricos e metodológicos que irão, efetivamente, contribuir para a resolução do problema proposto. Esse estudo deve ser bem documentado, possibilitando a utilização desses registros durante a composição do artigo científico.

Os apontamentos da documentação devem ser registrados em fichas, contendo as informações bibliográficas completas, o conteúdo central do documento, os elementos selecionados que darão suporte ao trabalho e citações entre aspas de afirmações feitas pelo autor, cuja relevância justifique sua inclusão no texto. É aconselhável que nas informações registradas pelo estudante seja utilizado vocabulário próprio, o que facilita a posterior utilização das mesmas.

O estudante deve ser observador para buscar novas idéias que possam ser aproveitadas 
no enfoque do conteúdo ou na forma de apresentação do trabalho. Essas idéias podem surgir durante a leitura do material bibliográfico ou em ambientes totalmente inesperados como numa peça de teatro, filmes, visitas a museus, em exposições literárias ou artísticas. $\mathrm{O}$ que foi visto e digno de nota pode enriquecer o trabalho e deve ser registrado em fichas para ser recuperado no momento oportuno.

Outras informações sobre a documentação podem ser obtidas nos livros que compõem as referências deste documento.

\section{ORGANIZAÇÃO DA EQUIPE}

As disciplinas POC I e POC II têm uma configuração diferente das demais disciplinas do curso. Há o professor responsável pelas disciplinas, designado como coordenador, e a equipe de orientadores. Cada aluno tem, portanto, dois mentores: o coordenador da disciplina e o orientador.

O coordenador é responsável pelo acompanhamento acadêmico do aluno e a coordenação da equipe dos orientadores. É ele quem faz, semestralmente, a distribuição de aluno/área temática/orientador; estabelece o cronograma das disciplinas, definindo as datas para a entrega das tarefas pelos alunos; e, das notas, pelos orientadores. Recebe as tarefas dos alunos nas datas estabelecidas e avalia os alunos em cerca de $20 \%$ dos pontos distribuídos; controla a freqüência dos mesmos, a pontualidade na entrega dos trabalhos e o lançamento das notas finais na secretaria da Instituição. Ainda, organiza e coordena o Seminário de Apresentação dos Trabalhos de POC; e, como mediador entre alunos e orientadores, procura resolver problemas entre as partes.

$\mathrm{O}$ orientador define com o aluno o tema e o problema a ser resolvido dentro da Área Temática escolhida pelo aluno. Dá apoio científico ao orientando durante o desenvolvimento do trabalho, estabelecendo as tarefas a serem cumpridas. Responsabiliza pela avaliação de cerca de $80 \%$ dos pontos distribuídos; e, integra, com um professor convidado, a banca examinadora, para a avaliação final no Seminário de Apresentação dos Trabalhos de POC.

O coordenador, a equipe de orientadores e os professores convidados que participam das bancas examinadoras compõem a Comissão Editorial da Revista Eletrônica POC.

\section{ESTRATÉGIAS DE AVALIAÇÃO}

A avaliação das duas disciplinas deve ser realizada durante o percurso do processo ensino/aprendizagem com função mais abrangente que um simples diagnóstico do desempenho do aluno. Conforme constata Moreira, em [17], "avaliar pressupõe reflexão e diálogo permanente entre todos os integrantes do processo ensino/aprendizagem" e a avaliação "deve ser exercida como uma atividade a serviço do conhecimento". Sendo assim, as interações orientador-coordenador/aluno e aluno/aluno devem ser constantes.

São utilizados no processo de avaliação os seguintes documentos:

1. Portfolio - Deve ser composto pelo aluno durante o curso para colecionar todo o material produzido e o fichamento do material consultado. O portfolio pode ser utilizado pelo aluno como fonte de consulta, reflexão sobre sua capacidade de organização, sobre sua atuação no curso e sobre o processo evolutivo de aprendizagem. $\mathrm{O}$ orientador pode solicitar a apresentação do portfolio nas sessões de orientação para acompanhar o desempenho, interesse e seriedade do aluno na condução de seu projeto.

2. Tarefas - O aluno deve cumprir as tarefas propostas pelo orientador-coordenador realizando-as sempre em tempo hábil à apreciação dos docentes para que sejam criticadas construtivamente, apresentando, se necessário, sugestões que possibilitem o 
aperfeiçoamento das mesmas. A entrega das tarefas, cuja pontualidade será avaliada, deve ser feita ao coordenador, que repassará aos orientadores.

3. Artigo Científico - É a apresentação formal de todo o desenvolvimento do projeto realizado. A versão definitiva deverá ser entregue ao final da disciplina POC II, entretanto, o aluno deve iniciá-lo com a primeira disciplina, permitindo que sua construção siga a dinâmica do projeto.

4. Seminário de Apresentação dos Trabalhos de POC - É o evento semestral que congrega alunos das duas disciplinas e outros interessados do Curso de Ciência da Computação, no qual os alunos de POC II apresentam oralmente o produto final do Trabalho de Conclusão de Curso para avaliação de uma Banca Examinadora. Com o objetivo de dar visibilidade aos trabalhos produzidos pelos graduandos e contribuir para a interação entre toda a comunidade do curso, a participação de todos os alunos tem motivação acadêmica. $\mathrm{O}$ evento possibilita mais um momento de aprendizagem, pois em se tratando de uma exposição de resultados de pesquisa, é fértil em idéias que motivam a proposição de novos trabalhos ou suscita a complementação dos mesmos. Ainda disponibiliza a aplicabilidade de conteúdos vistos no curso, além de revelar o aprofundamento destes conhecimentos ou temas inovadores. Os alunos que participam do seminário como ouvintes recebem certificados correspondendo a 1(uma) h/a de atividade complementar por seção presenciada e os de POC I devem assistir a duas apresentações obrigatoriamente.

5. Sessões de Orientação - São observados o comprometimento do aluno na execução das tarefas estabelecidas, o seu amadurecimento no desenvolvimento do tema, sua capacidade proativa para buscar bibliografia complementar, além da pontualidade e da assiduidade.

\section{ATIVIDADES DISCENTES}

Estão bem claros os objetivos do Projeto Orientado em Computação e, nas seções anteriores, foram oferecidas as diretrizes para atingi-los. Como o trabalho discente deve ser avaliado é prudente que esse processo se realize de maneira sistemática, envolvendo cada uma das fases de desenvolvimento do projeto. Por terem especificidades próprias é difícil estabelecer um conjunto de atividades que contemple a abordagem de todos os temas escolhidos. $\mathrm{Na}$ tentativa de uniformizar o processo foi criado um esquema de trabalho, que deve ser seguido, sempre que possível, pela dupla orientando/orientador. Entretanto, nas situações em que seja mais adequado substituí-lo por outro é esperado que as tarefas sejam constituídas de, pelo menos, duas ou três atividades diferentes para que a distribuição de pontos seja didaticamente correta.

A construção do artigo científico deve ser gradual e iniciada com a primeira tarefa. $\mathrm{O}$ texto é composto em dois eixos: horizontal e vertical. No eixo horizontal são definidos os tópicos a serem abordados e o eixo vertical contempla o aprofundamento da pesquisa realizada em cada um deles. $O$ pesquisador adquire maturidade no período de vigência da pesquisa e, certamente, elementos horizontais e verticais já elaborados sofrem alterações à medida que seu conhecimento é ampliado. Entretanto, mudanças realizadas numa estrutura já organizada são consideravelmente mais produtivas em relação às habituais incertezas detectadas no início do trabalho.

O Quadro I e o Quadro II sugerem as atividades, que devem compor as seis tarefas de cada uma das disciplinas. 
Quadro I

TAREFAS DE POC I

\begin{tabular}{|c|c|}
\hline Tarefa & \\
\hline I & $\begin{array}{l}\text { Leitura do Material } \text { Didático. } \\
\text { Escolha do tema da pesquisa, } \\
\text { definição do problema a ser } \\
\text { resolvido e o foco da abordagem } \\
\text { considerada com a especificação de } \\
\text { sua extensão e profundidade. }\end{array}$ \\
\hline II & $\begin{array}{l}\text { Histórico do problema. Objetivos e } \\
\text { justificativa. } \\
\text { bibliográfico. Fevantamento } \\
\text { Bibliografia básica. Esboço da } \\
\text { primeira seção do artigo científico (1 } \\
\text { Introdução), observando o exposto } \\
\text { no texto "Modelo do Artigo } \\
\text { Científico de POC" [3]. }\end{array}$ \\
\hline III & $\begin{array}{l}\text { Marco teórico do problema. } \\
\text { Especificação dos métodos e técnicas } \\
\text { utilizados para o desenvolvimento da } \\
\text { pesquisa. Identificação } \\
\text { ferramentas computacionais } \\
\text { darão suporte à resolução } \\
\text { problema. Coleta de dados ou } \\
\text { especificação do sistema } \\
\text { desenvolver. Esboço da segunda } \\
\text { seção do artigo científico, } \\
\text { observando o exposto no texto } \\
\text { "Modelo do Artigo Científico de } \\
\text { POC" [3]. }\end{array}$ \\
\hline IV & $\begin{array}{l}\text { Análise dos Dados ou finalização da } \\
\text { especificação do sistema em } \\
\text { desenvolvimento. } \\
\text { preliminar Elaboração } \\
\text { computacionais. dos } \\
\text { preliminar do artigo científico com a } \\
\text { inserção do material já produzido e } \\
\begin{array}{l}\text { delineamento de suas seções e } \\
\text { subseções. }\end{array}\end{array}$ \\
\hline V & Entrega do Portfolio. \\
\hline VI & $\begin{array}{l}\text { Participação como ouvinte em duas } \\
\text { seções do Seminário de } \\
\text { Apresentação dos Trabalhos de POC. }\end{array}$ \\
\hline
\end{tabular}

Quadro II

TAREFAS DE POC II

\begin{tabular}{|c|l|}
\hline Tarefa & \multicolumn{2}{|c|}{ Atividades } \\
\hline VII & $\begin{array}{l}\text { Conjunto de programas que } \\
\text { solucionam o problema. Testes } \\
\text { computacionais preliminares. } \\
\text { Elaboração da seção do artigo que } \\
\text { trata dos fundamentos teóricos que } \\
\text { embasa a pesquisa. }\end{array}$ \\
\hline VIII & $\begin{array}{l}\text { Testes computacionais finais. } \\
\text { Obtenção dos resultados. Versão } \\
\text { atualizada do artigo. }\end{array}$ \\
\hline IX & $\begin{array}{l}\text { Análise dos resultados. Conclusões e } \\
\text { recomendações. Versão atualizada } \\
\text { do artigo. }\end{array}$ \\
\hline X & $\begin{array}{l}\text { Revisão de linguagem do artigo. } \\
\text { Submissão do mesmo à Comissão } \\
\text { Científica da Revista Eletrônica } \\
\text { POC. }\end{array}$ \\
\hline XI & $\begin{array}{l}\text { Apresentação oral no Seminário de } \\
\text { Apresentação dos Trabalhos de POC. }\end{array}$ \\
\hline XII & $\begin{array}{l}\text { Entrega da versão final do artigo } \\
\text { científico (cópia digital em CD + } \\
\text { informações para a Biblioteca } \\
\text { Digital) após atendimento das } \\
\text { sugestões da Comissão Científica da } \\
\text { Revista Eletrônica POC. }\end{array}$ \\
\hline
\end{tabular}

A distribuição dos pontos encontra-se no Quadro III.

\section{Quadro III}

\section{DISTRIBUIÇÃO DOS PONTOS}

\begin{tabular}{|c|c|}
\hline Tarefas & Pontos \\
\hline I & 15 \\
\hline II, III, IV & 25 \\
\hline V, VI & 5 \\
\hline VII & 10 \\
\hline VIII & 25 \\
\hline IX & 20 \\
\hline X & 5 \\
\hline XI & 25 \\
\hline XII & 15 \\
\hline
\end{tabular}




\section{X. ÁREAS TEMÁTICAS}

O processo de definição do tema da pesquisa a ser desenvolvido pelo aluno para a elaboração de seu Trabalho de Conclusão de Curso é precedido pela escolha da área de estudo e a identificação do professor orientador.

O Quadro IV, dado a seguir, apresenta as Áreas Temáticas, que abrangem os conteúdos programáticos das disciplinas que compõem a estrutura curricular do curso.

\section{Quadro IV}

ÁREAS TEMÁTICAS

\begin{tabular}{|c|l|}
\hline N. $^{\text {}}$ & \multicolumn{1}{|c|}{ Área Temática } \\
\hline 1 & Arquitetura de Computadores \\
\hline 2 & Auditoria de Sistemas \\
\hline 3 & Banco de Dados \\
\hline 4 & Bioinformática \\
\hline 5 & Compiladores \\
\hline 6 & Computação Gráfica \\
\hline 7 & Engenharia de Software \\
\hline 8 & Informática na Saúde \\
\hline 9 & Inteligência Artificial \\
\hline 10 & Interface Homem-Máquina \\
\hline 11 & Pesquisa Operacional e Otimização \\
\hline 12 & Processamento de Imagens \\
\hline 13 & $\begin{array}{l}\text { Programação, Computação e } \\
\text { Algoritmos }\end{array}$ \\
\hline 14 & Recuperação de Informação \\
\hline 15 & Redes de Computadores \\
\hline 16 & Sistemas Distribuídos \\
\hline 17 & Sistemas multimídias \\
\hline 18 & Sistemas Operacionais \\
\hline 19 & Teoria dos Grafos \\
\hline
\end{tabular}

\section{AGRADECIMENTOS}

A autora agradece à Prof. ${ }^{a}$ Miriam Lourenço Maia, antiga coordenadora e ao Prof. Bráulio Roberto Gonçalves Marinho Couto, atual coordenador do Curso de Ciência da
Computação pela confiança depositada para a elaboração do projeto das disciplinas POC I e POC II, pela liberdade e apoio dispensados na implantação do projeto e na alteração do mesmo. Aos professores Leônidas Conceição Barroso, Cayley Guimarães, Sandra Maria Rodrigues de Morais e Maria de Lourdes Faleiro pelas discussões e sugestões apresentadas. À equipe de orientadores pela seriedade e competência demonstradas no desempenho da função e pelo trabalho compartilhado. Aos alunos, que, ao desenvolverem seus trabalhos, nos fizeram também aprendizes e orgulhosos do resultado obtido.

\section{REFERÊNCIAS}

[1] ANDRADE, Maria Margarida. Introdução à Metodologia do Trabalho Científico. São Paulo: Atlas, 1999.

[2] ARNOLD, Stela Beatris Tôrres. Planejamento em Educação a Distância. in Educação a Distância. vol. 2. Belo Horizonte: PUC Minas Virtual, 2002.

[3] BARROSO, M. M. A.; MAIA, M. L. Modelo do Artigo Científico de POC. Belo Horizonte: Uni-BH, 2009.

[4] ECO, Umberto. Como se faz uma tese. 17. ed. São Paulo: Perspectiva, 2002.

[5] FACHIN, Odília. Fundamentos de Metodologia. São Paulo: Atlas, 1993.

[6] FEITOSA, Vera Cristina. Redação de Textos Científicos. 3. ed. Campinas: Papirus, 1997.

[7] FRANÇA, Júnia Lessa. et al. Manual para Normalização de Publicações Técnico-Científicas. 3. ed. Belo Horizonte, UFMG, 1999.

[8] FRANCO, Iara Melo. Internet. in Educação a Distância. vol. 3. Belo Horizonte: PUC Minas Virtual, 2002.

[9] GIL, Antônio Carlos. Como Elaborar Projetos de Pesquisa. 3. ed. São Paulo: Atlas, 1991.

[10] GIUSTA, Agnela da Silva. Educação a Distância: contexto histórico e situação atual. in Educação a Distância. vol. 1. 
Belo Horizonte: PUC Minas Virtual, 2002.

[11] Concepções do

Processo Ensino/Aprendizagem. in Educação a Distância. vol. 1. Belo Horizonte: PUC Minas Virtual, 2002.

[12] HOUAISS, Antônio. Dicionário Houaiss da Língua Portuguesa. Rio de Janeiro: Objetiva, 2001.

[13] INÁCIO FILHO, Geraldo. $A$ monografia na Universidade. 3. ed. Campinas: Papirus, 1995

[14] MAIA, M. L.; COUTO, B. R. G. M Projeto Pedagógico do Curso de Ciência da Computação. Belo Horizonte: Uni-BH, 2003.

[15] MARTINS, Gilberto de Andrade. Manual para Elaboração de Monografias e Dissertações. São Paulo: Atlas, 2000.

[16] MICHEL, Maria Helena. Metodologia e Pesquisa Científica em Ciências
Sociais. São Paulo: Editora Atlas, 2005.

[17] MOREIRA, Mércia. O processo de avaliação em Cursos a Distância: reflexões. in Educação a Distância. vol. 2. Belo Horizonte: PUC Minas Virtual, 2002.

[18] PÁDUA, Elisabete Matallo Marchesini. Metodologia da Pesquisa - Abordagem Teórico-Prática. $6 . \quad$ ed. Campinas: Papirus, 2000.

[19] SEVERINO, Antônio Joaquim. Metodologia do Trabalho Científico. São Paulo: Cortez, 2002.

[20] SILVA, M. L. C.; MELO, N. H. P. L.; SOUZA, E. T. Manual para Elaboração e Normalização de Trabalhos Acadêmicos Conforme Normas da ABNT. Belo Horizonte: Uni-BH, 2008. $105 \mathrm{p}$. 